\title{
Choosing AMONg ANTITRUst LiabiLITY STANDARDS UNDER INCOMPLETE INFORMATION: ASSESSMENTS OF AND AVERSIONS TO THE RISK OF BEING WRONG
}

\author{
By Barbara Ann Wbite ${ }^{\dagger}$
}

David McGowan observes in his symposium article, Between Logic and Experience: Error Costs and United States v. Microsoft Corp. ${ }^{1}$ that conceivably in the realm of theory, the different schools of thought on how to evaluate and treat suspicious anticompetitive activity could coincide with each other. ${ }^{2}$ What prevents this from happening, he suggests, is that in the realm of reality, courts must make decisions under conditions of imperfect information, not only as to the anticompetitiveness of the scrutinized conduct but also as to the impact of their decisions, since incomplete information implies a risk that whatever the court decides, the decision is wrong. ${ }^{3}$ This yields the possibility of "error costs,", both of "false positives" (finding anticompetitive conduct when in fact it is welfareenhancing) and "false negatives" (finding the conduct efficient when in fact it is anticompetitive). McGowan argues that since the gaps in actual knowledge in any particular case must be overcome by certain leaps of faith, the guidelines an antitrust scholar advocates (or a particular court adopts) to evaluate specific conduct must to a certain extent turn on ideology; pure logic cannot resolve completely the uncertainty embedded in the incomplete information. ${ }^{5}$ As a corollary to his thesis, McGowan noted during the presentation that it would be interesting to explore why different antirust scholars adopt different ideological solutions to the logically unresolvable problems.

(C) Barbara Ann White

$\uparrow$ Associate Professor of Law, University of Baltimore; Chair, Section on Antitrust and Trade Regulation of the Association of American Law Schools. This Commentary discusses several papers presented at an antitrust panel, Evolving Antitrust Treatment of Dominant Firms, at the Association of American Law Schools (AALS) 2005 Annual Meeting. I wish to thank Steve Salop, David McGowan, Doug Melamed, and Alan Meese for useful comments.

1. David McGowan, Between Logic and Experience: Error Costs and United States v. Microsoft Corp., 20 BERKELEY TECH. L.J. 1185 (2005).

2. Id. at $1187,1244-45$.

3. Id. at 1187 .

4. Id. at $1186 \mathrm{n} .2$.

5. Id. at 1242 . 
The other two papers for this symposium, Douglas Melamed's article, Exclusionary Conduct Under the Antitrust Laws: Balancing, Sacrifice, and Refusals to Deal, ${ }^{6}$ and Steven Salop's paper, "Section 2, Consumer Welfare Effects, and the Flawed Profit-Sacrifice Standard,"7 each take their own approach regarding conduct evaluation. The two also discuss extensively the problem of error costs, albeit reaching different conclusions as to their impact and treatment. ${ }^{8}$ Melamed proposes a specifically defined measure of evaluating a firm's exclusionary conduct based on whether or not the conduct's profitability depends solely on rivals exiting, or the "profit sacrifice test," in order to expand on capturing false negatives without much sacrifice in the way of false positives. ${ }^{9}$ Salop proposes a more comprehensive evaluation by suggesting that courts consider the scrutinized conduct's overall impact on consumer welfare, or the "consumer welfare effects standard." Salop's proposal is to expand even further the capture of false negatives.

I agree with McGowan's overall analysis of the source of conflict between the current predominant views regarding the treatment of potentially anticompetitive conduct, particularly as it pertains to the conduct of dominant firms. I agree that the differences arise from the incomplete information that necessarily informs and renders uncertain the impact of decisions regarding firms' conduct. Though with additional analysis regarding whether antitrust decisions should be based on our experience rather than logic leads McGowan to conclude that his particular antitrust perspective-relying on the market rather than the courts for correction of anticompetitive conduct, or the "market correction approach"-is the superior one," I am more persuaded, within the same framework, by Melamed's more interventionist standard of the profit sacrifice test and am most persuaded by Salop's even more encompassing consumer welfare effects standard.

I also think McGowan's insight that the differences among scholars (and courts) are ideologic more than differences in logic can be usefully refined further. McGowan ascribes the source of ideological differences to the differences in faith in the marketplace versus faith in the government

6. A. Douglas Melamed, Exclusionary Conduct Under the Antitrust Laws: Balancing, Sacrifice, and Refusals to Deal, 20 BERKELEY TECH. L.J. 1247 (2005).

7. Steven Salop, Section 2, Consumer Welfare Effects, and the Flawed ProfitSacrifice Standard (May 11, 2005) (unpublished manuscript, on file with author).

8. Melamed, supra note 6, at 1257-61; Salop, supra note 7, at 53-54.

9. Melamed, supra note 6 , at 1255-57.

10. Salop, supra note 7 , at 3, 24-28, 48 .

11. McGowan, supra note 1 , at 1242-45. 
to regulate effectively, whether the errors are with regard to anticompetitive conduct or with regard to the errors in the decisions themselves. ${ }^{12}$ This suggests, for him, that the various points of view fall into one of two categories: either a market correction approach or an integrationist approach, in which consideration of the potential error costs of the decision are integrated into the decision process itself. ${ }^{13}$ McGowan advocates the former while Melamed and Salop presumably fall into the latter.

I believe, however, that the differences in viewpoint are affected not only by which correction tool a scholar or court find more effective (the market or the government), but also by the differences in their evaluation of the consequences of the false positives versus the false negatives in the specific instance under consideration. Inherent in any antitrust decision is a trade-off between the risk of a false positive and a false negative. As such, the differences in the valuation of those consequences may lead scholars and courts to differ in their reluctance to undertake the risks of particular outcomes when they choose to guard against one error as opposed to the other in a particular case. Therefore, I suggest that one's antitrust position is not only informed by one's belief in the ability of the marketplace relative to the government to correct anticompetitive problems, but also to the degree, in any particular circumstance, one is more riskaverse to the consequences of one error cost over the other. Incorporating a risk-averse analysis into the framework set forth by McGowan allows for a continuum of approaches rather than a stark categorization into two camps. This then allows for a distinction, in the context of that continuum, between Melamed's and Salop's papers. Thus, I would place McGowan's perspective-primary reliance on the marketplace-toward one end; Salop's perspective, which recommends a relatively broad and more finetuned government evaluation of conduct, toward the other; and Melamed's perspective of specific finite criteria to determine intervention, somewhere in the middle.

McGowan expands on his analysis of differences arising from the fusion of the ideologic with the logic by assessing how informative actual experience is with regard to practical application of the different views, as compared with what decisions the logic of these different views would dictate. He suggests that even though theoretical developments might guide us to more nuanced decision making in antitrust matters, the same element of imperfect information that requires us to supplement logical conclusions with ideological choices also compels us at times to choose

12. Id. at 1197-99.

13. Id. at $1186-88$. 
what experience tells us is a more effective practical course over what our theory would choose. ${ }^{14}$ McGowan uses the Microsoft case to prove his point: that at times experience (of the practicalities) should trump logic (no matter how insightful or far-reaching theory takes us in the theoretical plane). ${ }^{15}$ In particular, McGowan argues that though the Microsoft court couched its opinion in a theoretical framework which suggested a fairly strong integrationist approach, ultimately the actual liabilities and remedies accomplished very little in the way of change. ${ }^{16}$ This, he notes, is close to the outcome that would have occurred if a market correction approach had been adopted instead (and the case never brought). ${ }^{17}$ His analysis of the Microsoft case, therefore, argues for more reliance on the market correction approach for practical reasons even if, in theory, one supports a more integrationist approach. For McGowan, the Microsoft case even suggests that the integrationist approach is, in practical terms, a failure, as clearly the track record of government intervention has been rather abysmal, at least in the general purpose computing market. ${ }^{18}$

Unstated in McGowan's assertion - that the various approaches would coincide in theory if not for the practical impingement of imperfect information-is that, currently, most antitrust scholars adhere to the view that the goal is to maximize consumer welfare and therefore that standard should underlie antitrust judgments with regard to specific conduct. This, of course, contrasts with antitrust's past judicial history, when there was a strong sentiment in favor of preserving the number of competitors for its own sake as an ideal for maintaining competitive markets. This older standard gave way to the current view of judging conduct in light of consumer welfare in the wake of the Chicago School revolution. Certainly, not only is the consumer welfare standard implied by McGowan's discussion, ${ }^{19}$ it is also more explicitly expressed in both Melamed's and Salop's papers. ${ }^{20}$ Consumer welfare is a concept from economics, and to the extent that there is agreement among modern day antitrust scholars that not only is consumer welfare the benchmark by which business conduct should be

14. Id. at 1197-99.

15. Id. at 1211-12.

16. Id. at 1223-25.

17. Id. at $1244-45$.

18. Id. at 1189 .

19. Id. at 1188 .

20. Melamed, supra note 6 , at 1252 ("The principal function of an antitrust rule in a law enforcement regime is to create appropriate incentives for the avoidance of welfarereducing conduct."); Salop, supra note 7, at 2 ("[A]ntitrust law is said to be a 'consumer welfare prescription." "); see Salop, supra note 7, at 23-40 (describing further the consumer welfare standard). 
judged but also as to how it is defined, ${ }^{21}$ McGowan's assertion that the various views regarding antitrust treatment would coincide with each other in a world of perfect information is all the more convincing. ${ }^{22}$

In order to explain why I am most persuaded, within the context of McGowan's framework, by the approach at the other end of the continuum-Salop's consumer welfare effects standard-it might be useful to examine the ways the three papers fall along a continuum. The philosophies of the three papers might be summarized as follows.

McGowan's market correction view holds that the government, whether by court or administrative action, should only interfere with business conduct when the conduct is unambiguously anticompetitive in nature and, moreover, egregiously so. Any lesser standard increases the risk of a false positive, as more ambiguous conduct is more likely to be judged erroneously in violation of antitrust law. ${ }^{23}$ The subsequent interference by the government to "correct" this erroneously judged violation will cause a disruption in the workings of the marketplace, creating inefficiencies that are consumer welfare-reducing. ${ }^{24}$ This perspective recognizes that by leaving alone more ambiguous behavior, the false negatives that otherwise might have been caught, although welfare-reducing in the short term, will be remedied by forces the market will create to correct and, thus, remove the resultant inefficiencies. The assessment of the "market correctionists" is that harm done by the government from false positives (far) exceeds the harm done by false negatives because the market is more capable and efficient at correcting the latter than either the government or the market is able to correct the former. ${ }^{25}$ of course, this reflects the valuation assessment by those who support this view and demonstrates a high degree of risk averseness to the consequences of false positives.

21. There is debate as to what are the welfare measures that antitrust seeks or ought to seek to maximize - that is whether to maximize "consumer welfare" or "aggregate (or total) welfare." See Salop, supra note 7, at 24 n.58. There is also the issue of whether courts adopt the consumer welfare standard in section 2 cases. Alan Meese observes that some courts have rejected such an approach since 1955. E-mail from Alan Meese, Professor of Law, William \& Mary School of Law, to Barbara Ann White, Professor of Law, University of Baltimore School of Law (May 13, 2005) (on file with author).

22. One sometimes hears of positions such as Melamed's and Salop's as being of the old school view, in that they do focus on what happens to rivals in the course of the defendant firm's scrutinized conduct. Thus, it is important to recognize, as clearly McGowan does by implication, that observations of effects on rivals of particular conduct do not mean abandonment of the modern day measure of consumer welfare.

23. McGowan, supra note 1, at 1190-91.

24. Id.

25. Id. at 1189. 
Melamed advocates the profit sacrifice test. To a certain extent, the motivations underlying the test are concerns similar to the market correction approach, in that the goal is to create a standard that has a low probability of a false positive. ${ }^{26}$ The profit sacrifice test also has, however, the advantage of casting a wider net to capture true positives than does the market correction view. As Melamed defines the profit sacrifice test, the question is whether the incremental cost to the firm of the conduct under scrutiny exceeds the incremental revenues or cost savings the firm achieves (not including increased revenues or reduced costs that are due solely to rivals' exit as a result of the scrutinized conduct). ${ }^{27}$ If the incremental revenues exceed the incremental costs, then the activity makes sense for the firm to undertake (that is, it is profitable) regardless of whether rivals exit or not. The conclusion is then that the exit of the rivals is ancillary to the conduct and not an antitrust violation. However, if the conduct is profitable only if rivals exit- that is, without their exit, the firm would actually be sacrificing profits--then the profit sacrifice test concludes that the primary intent of the conduct is to exclude rivals from the market for profit purposes. ${ }^{28}$ Furthermore, the conduct is necessarily consumer welfare-reducing and thus properly condemned as anticompetitive. ${ }^{29}$ The advocates of the profit sacrifice test argue that this measure captures more of what would otherwise be false negatives under the market correction approach while not, in any significant way, increasing false positives.

The consumer welfare effects standard is a more wide-ranging balancing test than either of the other two. It is designed to cast a much broader net for true positives and, through government intervention, come closer to the goal of enhancing consumer welfare, the benchmark goal underlying all three views. ${ }^{30}$ The consumer welfare effects standard acknowledges an inherent problem in judging antitrust conduct, and that problem is, for the most part, that most business conduct has both procompetitive and anti-

26. Melamed, supra note 6, at 1257.

27. Id. at 1255-56.

28. Id.

29. Melamed notes that it is not necessary for the firm to "sacrifice" profits-that is, lose profits but for the exit of the rivals-for the conduct to fail profit sacrifice test. Presumably, even if the conduct was a break-even proposition for the firm without its rivals exiting but profitable upon their exit, then the inference would be that the intent behind the conduct was merely anticompetitive and would still be condemned. Id.

30. Salop emphasizes that the consumer welfare effects standard focuses solely on the welfare of consumers and not on aggregate welfare. See Salop, supra note 7, at 24 n.58; discussion supra note 21 . 
competitive effects. ${ }^{31}$ In other words, with most business activity, one can find welfare-enhancing as well as welfare-reducing aspects. The court's task is to weigh the factual evidence of welfare enhancement against the evidence of welfare reduction and if the enhancement exceeds the reduction the firm is not held liable; vice versa, the firm is found in violation of the antitrust laws. ${ }^{32}$

The primary criticism of the market correction approach is fairly obvious: it leaves too many false negatives - that is, it leaves too many firms engaging in welfare-reducing conduct unconstrained. Those who critique the market correction approach, as McGowan says, do not have much faith in the market to correct false negatives. ${ }^{33}$ The advocates of both the profit sacrifice test and the consumer welfare effects standard-or, as McGowan would have it, the integrationists-assess the persistence of the welfare reduction from the exclusionary behavior of dominant firms as a much graver consequence than do the market correctionists. The integrationists not only perceive the government as capable of properly assessing anticompetitive conduct, but they also evaluate the consequences of the false positives as less severe than do the market correctionists. ${ }^{34}$ Typically, the integrationists also see the consequential effects of false positives as much less than the consequential effects of the false negatives if those conducts are left unchecked. ${ }^{35}$ Thus, the integrationists are highly motivated to find and refine the tools the government can employ to gauge more correctly the net welfare effects of specific business conduct.

The criticism of the profit sacrifice test, from the perspective of the market correctionists, is the perceived increase in the risk of false positives, ${ }^{36}$ which the market correctionists evaluate at a very high cost to society. The advocates of the consumer welfare effects standard-the consumerists-view the profit sacrifice test as good but not enough. The profit sacrifice test alone is not sufficient to capture as many of the true positives as the consumerists believe is possible, and thus leaves too many false negatives for the consumerists' comfort. More than the profit sacrifice test is needed and is possible, the consumerists argue. Salop, through an example of suspect predatory pricing, asserts that the profit sacrifice test may create a false positive and thus it may fail in its effort to increase

31. Salop, supra note 7 , at 47 .

32. Id. at 52-54.

33. McGowan, supra note 1, 1192-93.

34. See, e.g., id. at 1192-99.

35. See, e.g., id.

36. Melamed, supra note 6 , at 1259-60. 
the number of true positives (that is, reduce the number of false negatives) without simultaneously increasing the number of false positives. ${ }^{37}$

The supporters of the profit sacrifice test argue in their defense that the test yields a fairly simple and straightforward rule that not only is relatively easy for jurists to apply but also creates a measure of certainty for firms, assuring that the firms can continue to engage in innovative procompetitive conduct without being caught in a tangled net of antitrust accusations that may have no merit. ${ }^{38}$ Clearly, the advocates of the profit sacrifice test weigh the consequences of false negatives far more heavily than the market correctionists, but like the market correctionists, they also measure the consequences of false positives fairly strongly. The profit sacrifice test seems to its supporters to take skillful advantage of the economic insights into the workings of the firm to fashion a rule that captures anticompetitive conduct with more precision than previous standards with small risk of increasing false positives. This middle ground, to its supporters, seems to be the best of all choices. The test also appeals to our instinct that a profit-maximizing firm would not forgo profits unless it anticipates recouping them at some later date.

The primary criticism of the consumer welfare effect standard is that its biggest advantage is also its biggest disadvantage. This is also when McGowan's "experience ought to trump logic in the world of practicalities" argument has its most persuasive import. The consumer welfare effect standard is a broader-ranged nuanced analysis requiring examination of the impact of scrutinized conduct on consumers' welfare overall, with particular attention paid to price, quality, and innovation. ${ }^{39}$ In addition, the standard considers a much broader range of conduct. Though in theory this has great appeal because it addresses directly the presumptive goal of antitrust-maximizing consumer welfare - and it should reduce dramatically the likelihood of false negatives, from a practical perspective, its critics hold that its application is untenable. Judges are not skilled enough to evaluate the complex economic arguments and data analyses asserting consumer welfare enhancement or reduction, nor are they able to properly weigh the measures of the two to conclude what the net effects are. Juries are even less capable. Moreover, even examining data to put forth plaintiff or defendant arguments is extremely difficult and expensive, taking great

37. Salop, supra note 7, at 19-20.

38. Melamed, supra note 6, 1256-27.

39. Salop, supra note 7 , at $3-4,25$. 
talent and skill. To some, it seems perhaps impossible to achieve properly. ${ }^{40}$

That is one of the points McGowan makes in his article with regard to the Microsoft case. There the very best analysts in the country argued on both sides. In theory the court sided with the consumerists in its analysis but concluded with a "tapioca pudding" of effect. ${ }^{41}$ McGowan argues that the conduct that was in fact most market-enhancing for Microsoft went unpunished and the conduct with trivial implications was what was sanctioned with trivial results. $^{42}$

Finally, a serious problem with a welfare approach for evaluating conduct is that each case is very situation specific. The welfare effects standard creates an environment with limited precedential value. Businesses will not know how to proceed when desiring to undertake innovation; what seems like an arbitrary antitrust web may fall on them at any time, and is more likely to do so the more successful they are, as great success usually breeds the exit of others. Some argue that the welfare effects approach could hamper creativity and economic progress. ${ }^{43}$ Even if it could be properly implemented, the welfare effect standard seems doomed not to succeed.

Thus, the consumer welfare effect standard seems to be a paradigm of what McGowan was referring to in his argument that sometimes experience should trump logic. The consumer welfare effect standard is essentially perfect in theory, comporting precisely and logically with all modern scholars' views that the goal of antitrust law should be consumer welfare enhancement. But in practice, given its complexity, the difficulties in implementing it effectively, and its confusing implications for predictable precedent,the consumer welfare effects standard seems doomed to failure. Experience seems to tell us that this logic should be trumped.

With such dire evaluations, why then might the consumer welfare effects standard seem the most persuasive? There are several reasons.

First, its appeal does not rely just on a lack of faith in the market correction approach. The appeal is more than just ideologic. Not only is the lack of faith in the market's ability to correct anticompetitive behavior a factor, but also the recognition of the unlikelihood that, even when the market does manage to move the actors to more efficient conduct, the in-

40. See Melamed, supra note 6, at 1253-54. Melamed also concludes that such balancing tests would improperly evaluate product innovation and price-cutting behavior, as well. See id. at 1267.

41. McGowan, supra note 1 , at 1189.

42. Id. at 1226 .

43. See, e.g., Melamed, supra note 6, at 1253-54. 
dustry will now progress on an economic path that is the not one consumers would have chosen but for the initial anticompetitive conduct. It is one thing for the marketplace to move all parties to some efficient conduct, it is another to adopt the same efficient path that was emerging before the exclusionary conduct.

Despite the fact that economic efficiency is often expressed as synonymous with maximizing welfare-it is not. Efficiency is, of course, a necessary condition for a maximally welfare-enhancing allocation of resources. However, more than firms operating efficienctly is needed. What is well-known by those steeped in economic analysis of antitrust law but seems to have been forgotten-or at least not mentioned during discussions of antitrust issues-is that there is not a sole, unique economically efficient path on which an economy can progress. As basic economic analysis teaches us, for every given allocation of initial resources, there are a multitude of efficient paths; and for every set of initial resources, there are multiple efficient allocations. It is the interaction of constraints from different sources outside the marketplace as well as efficiency forces within the marketplace that affect which of these economic paths will be followed. Much of the outside force is derived from consumer preferences, but other factors can affect the direction as well. Anticompetitive behavior at critical points in an industry's development can alter the direction of economic progress and is likely to do so counter to consumer preferences.

It is in that context that full faith in market correction of anticompetitive conduct seems, at best, tenuous. Though most agree that inefficiency by firms will be eroded by market forces-and anticompetitive behavior is typically viewed as inefficient-it is not convincing that the efficient path the industry will now be on, post-anticompetitive behavior, is the same as the efficient one that consumers would have preferred. After all, the path is one geared to a dominant firm's conduct designed to enhance its own economic welfare through the means of subverting consumer choice.

Anticompetitive conduct is by definition undermining consumer choice. It is necessary for a dominant firm to use these tactics to exclude rivals only if enough consumers prefer the rivals' products and the dominant firm cannot woo them otherwise. So although, in the long run, the market may move to make the dominant firm efficient once again, it will be efficient around the direction generated by the firm, against the consumers' wishes and without, perhaps; preferred rivals.

This view clearly affects one's risk analysis of consequences of error costs and will also lead to an evaluation of the costs of false negatives as being very high. It cautions decision makers to be risk averse to decisions that leave open increases in false negatives. 
The profit sacrifice test therefore has great appeal compared to the market correction approach, for all the reasons those who advocate the profit sacrifice test suggest: it probes the implication of a firm's conduct more thoroughly and thus is more able to capture true negatives than the market correction approach (its improvement over the older AreedaTurner test has been much discussed in the literature); it has clarity and simplicity, making it easier for courts to apply; and it can provide sufficient precedential value to guide firms as to what will be considered problematic aggressive conduct when battling it out in the marketplace.

However, there was a brief discussion of a point during another presentation of these viewpoints that struck me and caused me to shift in favor of the consumer welfare effects test. ${ }^{44}$ The shift in position is also consistent with McGowan's view that sometimes experience ought to trump logic. The discussion was with regard to what the effect would be on firms if the courts indeed adopted a consumer welfare effects standard. It was suggested that firms would probably, right from the start, begin accruing evidence that their conduct enhanced consumer welfare over any reduction. This implies that dominant firms would engage in their own consumer welfare effects analysis when evaluating a new course of conduct, and, though motivated by antitrust concerns, this self-evaluation would ultimately benefit consumers because of its impact on the firms' decisionmaking process.

If this is correct, other advantages would occur as well. As it becomes standard for firms to incorporate consumer welfare assessments along with the other measures of feasibility and profitability of any new venture, a likely outcome is that the means and methods of measuring such effects will improve over time. It also suggests that the plaintiffs and defendants will become more efficient at presenting cogent evidence and courts more efficient at evaluating net consumer welfare benefits. Experience teaches us that implementing legal standards to create incentives for the actors to better achieve certain social goals is effective. Certainly we have found that the implementation of the exclusionary rule under the Fourth Amendment dramatically improved police investigative activity, occupational health and safety laws have made the workplace dramatically safer, and product liability for design defects has caused firms to produce far safer goods than in the past century.

Though it is has been debated for sometime now whether the implementation of these standards in other areas of law has gone too far, there is

44. This discussion took place at the American Bar Association Section of Antitrust Law Annual Spring Meeting (Mar. 30, 2005). 
no question regarding the vast improvement in these matters compared with over a century ago. Thus, if it becomes routine in the corporate world to incorporate consumer welfare analysis in the decision-making process, this atmosphere will permeate throughout the market system. The effect is likely to motivate firms to be more consistent with the goals of antitrust law, and the firms are likely to give consumer welfare effect its best and most efficient expression. Experience teaches us so. 